\title{
Course Evaluation Model and Its Application Based on Grey Correlation Analysis Method
}

\author{
Tao Wang ${ }^{1,}$, Zheng Tang $^{1}$ \\ ${ }^{1}$ Basic Courses Department, Bengbu Automobile Non-Commissioned Officer Academy, Bengbu \\ 233011, China \\ asuperwt@qq.com
}

Keywords: Index course evaluation; ideal solving method; grey correlation analysis method; Euclidean distance

\begin{abstract}
Combining ideal solving method and Euclidean distance, the article constructs a new course evaluation model based on grey correlation analysis method. First, idealizes and standardizes the quantitatively treated evaluation indicators, constructs positive and negative incidence matrix. Then, defines grey correlation distance degree, puts forward an evaluation way close to the optimal solution and far from the worst one. At last, introduces the actual use of model by combining a course evaluation, and tests its accuracy and feasibility.
\end{abstract}

\section{Introduction}

Evaluation, is the act and process, in which the professional organizations and staff, choosing appropriate way, using scientific method, to analyze the object, budget, make decisions and deliver professional opinions according to certain standards, specific aims, and relative procedures. Education evaluation is the booster of the higher schools' construction, innovation and development, and the effective measures to elevate higher education's quality. As an important part, course evaluation is developing with education evaluation. Among much education evaluation home and abroad, course evaluation is a top priority, and many of the evaluation models are even directly based on it. On the one hand, course evaluation exists as an important indicator of various types of comprehensive education evaluation; on the other hand, the administrative department of education carries out the course evaluation as an important means of course construction from top to bottom, so the course evaluation attracts more and more attention [1.2].

Now, course evaluation analyzes the course mainly in quality in some ways then makes the evaluation, or adopts "centesimal system evaluation" and "indicator evaluation". The limitations of these methods decide that they can hardly reflect the relative merits of course plan accurately and objectively. In fact, the factors which influence course plan are various, and to what extent are different. Among them are qualitative and quantitative factors, some of the factors are only fit for description generally, and has the grey character, that is to say, part of the information is known, and part of it is unknown, so it can be tackled by using grey system theory [3]. The article puts grey correlation analysis method in course evaluation by combining ideal solving method and Euclidean distance, aiming to provide an objective and accurate handling method for administrative department in charge of education when take course evaluation.

\section{Model of course evaluation}

Suppose there are $n$ courses waiting for evaluation, notes course set as $X=\left\{X_{1}, X_{2}, \ldots, X_{n}\right\}$; if each course has $m$ evaluation indicators, notes indicator set as $V=\left\{V_{1}, V_{2}, \ldots, V_{n}\right\}$, indicator number course $\mathrm{X}_{\mathrm{j}}$ towards indicator $\mathrm{V}_{\mathrm{i}}$ marks as $\mathrm{c}_{\mathrm{ij}}(\mathrm{i}=1,2, \ldots, \mathrm{m} ; \mathrm{j}=1,2, \ldots, \mathrm{n})$, so the evaluation matrix $\mathrm{C}$ which $\mathrm{n}$ courses towards $\mathrm{m}$ indicators is constructed:

$$
C=\left(c_{i j}\right)_{m \times n}=\left(\begin{array}{ccc}
c_{11} & \cdots & c_{1 n} \\
\vdots & \ddots & \vdots \\
c_{m 1} & \cdots & c_{m n}
\end{array}\right)
$$


Idealized. Idealizing the elementary matrix is to add the optimal and the worst referential evaluation plan. The optimal evaluation plan is the positive ideal one, that is, the optimal number each indicator can reach among all the evaluation plans; the worst evaluation plan is the negative ideal one, that is, the worst number each indicator can reach among all the evaluation plans.

Positive ideal elementary evaluation matrix. The sequence of $i$ evaluation plan among the elementary evaluation matrix is $\mathrm{c}_{\mathrm{i}}=\left(\mathrm{c}_{\mathrm{i} 1}, \mathrm{c}_{\mathrm{i} 2}, \ldots, \mathrm{c}_{\mathrm{in}}\right), \mathrm{i}=1,2, \ldots, \mathrm{m}$. Constructing the optimal referential sequence as $c_{0}^{+}=\left(c_{01}, c_{02}, \cdots, c_{0 n}\right)$. When $C_{j}$ is useful indicator, $c_{0 j}=\max \left\{c_{1 j}, c_{2 j}, \ldots, c_{m j}\right\}$. When $C_{j}$ is damageable indicator, $\mathrm{c}_{0 \mathrm{j}}=\min \left\{\mathrm{c}_{1 \mathrm{j}}, \mathrm{c}_{2 \mathrm{j}}, \ldots, \mathrm{c}_{\mathrm{mj}}\right\}$. When $\mathrm{C}_{\mathrm{j}}$ is moderate indicator, $c_{0 j}=c_{0 j}^{\prime}$. Among them, $c_{0 j}^{\prime}$ is moderate quality number of $\mathrm{C}_{\mathrm{j}}$.

Matrix $\mathrm{C}^{+}=\left(\mathrm{c}_{\mathrm{ij}}\right)_{(\mathrm{m}+1) \mathrm{n}}$ constructed here is positive ideal elementary evaluation matrix of evaluation indicator, among them, $i=1,2, \ldots, m ; j=1,2, \ldots, n$.

Negative ideal elementary evaluation matrix. Constructing the worst referential sequence as $c_{0}^{-}=\left(c_{01}, c_{02}, \cdots, c_{0 n}\right)$. When $\mathrm{C}_{\mathrm{j}}$ is useful indicator, $\mathrm{c}_{0 \mathrm{j}}=\min \left\{\mathrm{c}_{1 \mathrm{j}}, \mathrm{c}_{2 \mathrm{j}}, \ldots, \mathrm{c}_{\mathrm{mj}}\right\}$. When $\mathrm{C}_{\mathrm{j}}$ is damageable indicator, $\quad \mathrm{c}_{0 \mathrm{j}}=\max \left\{\mathrm{c}_{1 \mathrm{j}}, \mathrm{c}_{2 \mathrm{j}}, \ldots, \mathrm{c}_{\mathrm{mj}}\right\}$. When $\mathrm{C}_{\mathrm{j}}$ is moderate indicator, $c c_{j}=\max \left\{\left|c 1 j-c_{0 j}^{\prime}\right|,\left|c 2 j-c_{0 j}^{\prime}\right|, \cdots,\left|c m j-c_{0 j}^{\prime}\right|\right\}$. Among them, $c_{0 j}^{\prime}$ is moderate quality number of $\mathrm{C}_{\mathbf{j}}$.

Matrix $\mathrm{C}^{-}=\left(\mathrm{c}_{\mathrm{ij}}\right)_{(\mathrm{m}+1) \mathrm{n}}$ constructed here, is negative ideal elementary evaluation matrix of evaluation indicator, among them, $i=1,2, \ldots, m ; j=1,2, \ldots, n$.

Standardization. Due to the difference of each indicator's quality, dimension, the above matrix $\mathrm{C}^{ \pm}$ needs to be standardized for the sake of comparison. Use Eq. 1 to standardize the useful indicators in matrix $\mathrm{C}^{+}$and damageable indicators in matrix $\mathrm{C}^{-}$.

$$
\mathrm{u}_{\mathrm{ij}}=\mathrm{c}_{\mathrm{ij}} / \mathrm{c}_{0 \mathrm{j}} \mathrm{i}=1,2, \ldots, \mathrm{m} ; \mathrm{j}=1,2, \ldots, \mathrm{n}
$$

Among them $\mathrm{c}_{\mathrm{ij}}$ is elementary sequence, $\mathrm{c}_{0 \mathrm{j}}$ is referential sequence.

For the damageable indicators in matrix $\mathrm{C}^{+}$and useful indicators in matrix $\mathrm{C}^{-}$, use Eq. 2 to standardize.

$$
\mathrm{u}_{\mathrm{ij}}=\mathrm{c}_{0 \mathrm{j}} / \mathrm{c}_{\mathrm{ij}} \mathrm{i}=1,2, \ldots, \mathrm{m} ; \mathrm{j}=1,2, \ldots, \mathrm{n}
$$

Among them $\mathrm{c}_{\mathrm{ij}}$ is elementary sequence, $\mathrm{c}_{0 \mathrm{j}}$ is referential sequence.

Use Eq. 3 to standardize the moderate indicators.

$$
\mathrm{u}_{\mathrm{ij}}=\min \left(\mathrm{c}_{\mathrm{ij}}, \mathrm{c}_{0 \mathrm{j}}\right) / \max \left(\mathrm{c}_{\mathrm{ij}}, \mathrm{c}_{0 \mathrm{j}}\right) \mathrm{i}=1,2, \ldots, \mathrm{m} ; \mathrm{j}=1,2, \ldots, \mathrm{n}
$$

Among them, $c_{0 j}^{\prime}$ is moderate quality figure of indicator $\mathrm{C}_{\mathbf{j}}$.

Standard ideal evaluation matrix $\mathrm{C}^{ \pm}$is obtained after the standardization of the ideal elementary evaluation matrix $\mathrm{C}^{ \pm}$.

Incidence matrix. In the standardized ideal matrix, data sequence $\mathrm{c}_{0 \mathrm{j}}=\left(\mathrm{c}_{01}, \mathrm{c}_{02}, \ldots, \mathrm{c}_{0 \mathrm{n}}\right)$ is referential sequence, $\mathrm{c}_{1 \mathrm{j}}, \mathrm{c}_{2 \mathrm{j}}, \ldots, \mathrm{c}_{\mathrm{mj}}$ is comparative sequence, then correlative coefficient between the number $\mathrm{j}$ indicator in the number $i$ evaluation plan and number $\mathrm{j}$ indicator in the referential sequence is

$$
\varepsilon_{i j}=\frac{\min _{i} \min _{j}\left|c_{0 j}-c_{i j}\right|+\rho_{i} \max _{j} \max _{j}\left|c_{0 j}-c_{i j}\right|}{\left|c_{0 j}-c_{i j}\right|+\rho_{i} \max _{j} \max _{j}\left|c_{0 j}-c_{i j}\right|} \quad \mathrm{i}=1,2, \ldots, \mathrm{m} ; \mathrm{j}=1,2, \ldots, \mathrm{n}
$$

Among them, $\rho$ is called resolution ratio, generally the number we take is 0.5 .

Correlative coefficient on all line vectors in the standardized ideal evaluation matrix $\mathrm{U}^{ \pm}$is respectively obtained according to the optimal and the worst referential sequences. Then the matrixes made of correlative coefficient are formed, which are called positive incidence matrix $\mathrm{D}^{+}$and negative incidence matrix $\mathrm{D}^{-}$.

$$
D^{+}=\left(\begin{array}{cccc}
\varepsilon_{01}^{+} & \varepsilon_{02}^{+} & \cdots & \varepsilon_{0 n}^{+} \\
\varepsilon_{11}^{+} & \varepsilon_{12}^{+} & \cdots & \varepsilon_{1 n}^{+} \\
\vdots & \vdots & \ddots & \vdots \\
\varepsilon_{m 1}^{+} & \varepsilon_{m 2}^{+} & \cdots & \varepsilon_{m n}^{+}
\end{array}\right)
$$




$$
D^{-}=\left(\begin{array}{cccc}
\varepsilon_{01}^{-} & \varepsilon_{02}^{-} & \cdots & \varepsilon_{0 n}^{-} \\
\varepsilon_{11}^{-} & \varepsilon_{12}^{-} & \cdots & \varepsilon_{1 n}^{-} \\
\vdots & \vdots & \ddots & \vdots \\
\varepsilon_{m 1}^{-} & \varepsilon_{m 2}^{-} & \cdots & \varepsilon_{m n}^{-}
\end{array}\right)
$$

Each indicator's weight can be determined by the Analytic Hierarchy Process. The weighted incidence matrix is obtained by set weight multiplies each column in the incidence matrix.

Incidence distance. In the incidence matrix, the first row represents the optimal referential sequence plan and the worst one. The nearer it approached the optimal figure, the better Evaluation result shows. The nearer it approached the worst figure, the worse the evaluation result shows. This article adopts the Euclidean distance as the measuring standard. In the positive and negative matrix $\mathrm{D}^{ \pm}$, calculate the Euclidean distance in each comparative sequence plan according to the optimal and the worst referential sequence.

$$
L_{i}^{ \pm}=\sqrt{\sum_{j=1}^{n}\left(\varepsilon_{i j}^{ \pm}-\varepsilon_{0 j}^{ \pm}\right)^{2}}, \quad \mathrm{i}=1,2, \ldots, \mathrm{m}
$$

and define grey correlation distance degree R.

$$
R_{i}=\frac{L_{i}^{+2}}{L_{i}^{+2}+L_{i}^{-2}}
$$

Sorting the list by the figure of grey correlation distance degree $\mathrm{R}_{\mathrm{i}}$ from small to large represents the order of comparative sequence. The smaller the $\mathrm{R}_{\mathrm{i}}$ 's figure is, the nearer it approaches the optimal plan.

Different types of evaluation are obtained according to the definition of correlation distance degree and large amount of data of experts. The figure of $R_{i}$ is within a range of $[0,0.2)$, the evaluation type is $A$. The figure of $R_{i}$ is in a range of $[0.2,0.5)$, the evaluation type is $B$. The figure of $R_{i}$ is in a range of $[0.5,0.8)$, the evaluation type is $C$. The figure of $R_{i}$ is in a range of $[0.8,1.0]$, the evaluation type is $D$.

According to the above analysis, course evaluation algorithm can be summarized as follows [4]:

1) Elementary course evaluation matrix $C$ is obtained by quantifying each course evaluation indicator.

2) Constructing ideal elementary evaluation matrix $\mathrm{C}^{ \pm}$on the positive and negative ideal course plan.

3) Standardized evaluation matrix $U^{ \pm}$is obtained by eliminating different measurement in each indicator and then nondimensionalizing them.

4) According to the standardized evaluation matrix, calculate correlative coefficient which every evaluation indicator of each course relative to positive and negative ideal evaluation plan, then constructs incidence matrix $\mathrm{D}^{ \pm}$.

5) The indicator's weight determines weighting incidence matrices.

6) In the incidence matrices, the distance of each course relative to positive and negative ideal evaluation plan is calculated. Grey correlation distance degree of each course is calculated.

7) Sort and classify the incidence matrices in ascending order according to grey correlation distance degree, then evaluate the courses.

\section{Case analysis}

We choose 6 indicators such as teachers, teaching conditions, teaching reform, teaching hours, innovative education, and teaching effect to evaluate construction of one course in 5 schools by combining the course's features. Among them, teaching hours is a moderate indicator, the rest are useful indicators. Each course evaluation table is established through questionnaire, experts' evaluation and Delphi. 
Table 1 Evaluation figure of a course in five schools

\begin{tabular}{|l|c|c|c|c|c|c|}
\hline & $\begin{array}{c}\text { Teaching } \\
\text { staff }\end{array}$ & $\begin{array}{c}\text { Teaching } \\
\text { conditions }\end{array}$ & $\begin{array}{c}\text { Teaching } \\
\text { reform }\end{array}$ & $\begin{array}{c}\text { Teaching } \\
\text { hours }\end{array}$ & $\begin{array}{c}\text { Innovative } \\
\text { education }\end{array}$ & $\begin{array}{c}\text { Teaching } \\
\text { effect }\end{array}$ \\
\hline $\mathrm{C}_{1}$ & 0.864 & 0.833 & 0.875 & 1 & 0.792 & 0.903 \\
\hline $\mathrm{C}_{2}$ & 0.762 & 0.805 & 0.836 & 0.941 & 0.813 & 0.896 \\
\hline $\mathrm{C}_{3}$ & 0.719 & 0.748 & 0.763 & 0.889 & 0.678 & 0.735 \\
\hline $\mathrm{C}_{4}$ & 0.794 & 0.739 & 0.840 & 0.889 & 0.785 & 0.872 \\
\hline $\mathrm{C}_{5}$ & 0.723 & 0.777 & 0.817 & 0.937 & 0.733 & 0.813 \\
\hline
\end{tabular}

Step 1: elementary evaluation matrix is obtained according to table 1

$$
C=\left(\begin{array}{cccccc}
0.864 & 0.833 & 0.875 & 1 & 0.792 & 0.903 \\
0.762 & 0.805 & 0.836 & 0.941 & 0.813 & 0.896 \\
0.719 & 0.748 & 0.763 & 0.889 & 0.678 & 0.735 \\
0.794 & 0.739 & 0.84 & 0.889 & 0.785 & 0.872 \\
0.723 & 0.777 & 0.817 & 0.937 & 0.733 & 0.813
\end{array}\right)
$$

Step 2: positive and negative ideal elementary evaluation matrix are obtained by idealized

$$
\begin{aligned}
C^{+} & =\left(\begin{array}{cccccc}
0.864 & 0.833 & 0.875 & 1 & 0.813 & 0.903 \\
0.864 & 0.833 & 0.875 & 1 & 0.792 & 0.903 \\
0.762 & 0.805 & 0.836 & 0.941 & 0.813 & 0.896 \\
0.719 & 0.748 & 0.763 & 0.889 & 0.678 & 0.735 \\
0.794 & 0.739 & 0.84 & 0.889 & 0.785 & 0.872 \\
0.723 & 0.777 & 0.817 & 0.937 & 0.733 & 0.813
\end{array}\right) \\
C^{-} & =\left(\begin{array}{cccccc}
0.719 & 0.739 & 0.763 & 0.889 & 0.678 & 0.735 \\
0.864 & 0.833 & 0.875 & 1 & 0.792 & 0.903 \\
0.762 & 0.805 & 0.836 & 0.941 & 0.813 & 0.896 \\
0.719 & 0.748 & 0.763 & 0.889 & 0.678 & 0.735 \\
0.794 & 0.739 & 0.84 & 0.889 & 0.785 & 0.872 \\
0.723 & 0.777 & 0.817 & 0.937 & 0.733 & 0.813
\end{array}\right)
\end{aligned}
$$

Step 3: positive and negative ideal evaluation matrix $U^{ \pm}$is obtained according to Eq. $1 \sim 3$

$$
\begin{aligned}
U^{+} & =\left(\begin{array}{cccccc}
1 & 1 & 1 & 1 & 1 & 1 \\
1 & 1 & 1 & 1 & 0.974 & 1 \\
0.882 & 0.966 & 0.955 & 0.941 & 1 & 0.992 \\
0.832 & 0.898 & 0.872 & 0.889 & 0.834 & 0.814 \\
0.919 & 0.887 & 0.96 & 0.889 & 0.966 & 0.966 \\
0.837 & 0.933 & 0.934 & 0.937 & 0.902 & 0.901
\end{array}\right) \\
U^{-} & =\left(\begin{array}{cccccc}
1 & 1 & 1 & 1 & 1 & 1 \\
0.832 & 0.887 & 0.887 & 0.889 & 0.856 & 0.814 \\
0.944 & 0.918 & 0.913 & 0.945 & 0.834 & 0.82 \\
1 & 0.988 & 1 & 1 & 1 & 1 \\
0.906 & 1 & 0.908 & 1 & 0.864 & 0.843 \\
0.994 & 0.951 & 0.934 & 0.949 & 0.925 & 0.904
\end{array}\right)
\end{aligned}
$$


step4: positive and negative incidence matrix are obtained according to Eq. 4

$$
\begin{aligned}
D^{+} & =\left(\begin{array}{cccccc}
1 & 1 & 1 & 1 & 1 & 1 \\
1 & 1 & 1 & 1 & 0.781 & 1 \\
0.441 & 0.732 & 0.674 & 0.612 & 1 & 0.921 \\
0.356 & 0.477 & 0.421 & 0.456 & 0.359 & 0.333 \\
0.534 & 0.451 & 0.699 & 0.456 & 0.732 & 0.732 \\
0.363 & 0.581 & 0.585 & 0.596 & 0.487 & 0.484
\end{array}\right) \\
D^{-} & =\left(\begin{array}{cccccc}
1 & 1 & 1 & 1 & 1 & 1 \\
0.356 & 0.451 & 0.451 & 0.456 & 0.392 & 0.333 \\
0.624 & 0.531 & 0.517 & 0.628 & 0.359 & 0.341 \\
1 & 0.886 & 1 & 1 & 1 & 1 \\
0.497 & 1 & 0.503 & 1 & 0.406 & 0.372 \\
0.939 & 0.655 & 0.585 & 0.646 & 0.554 & 0.492
\end{array}\right)
\end{aligned}
$$

step5: Based on the weight the evaluation experts give to each indicator, the weighted incidence matrix is obtained form $\mathrm{W}=(0.15,0.15,0.25,0.15,0.1,0.2)$

$$
\begin{aligned}
D_{W}^{+} & =\left(\begin{array}{cccccc}
0.15 & 0.15 & 0.25 & 0.15 & 0.1 & 0.2 \\
0.15 & 0.15 & 0.25 & 0.15 & 0.0781 & 0.2 \\
0.0662 & 0.1098 & 0.1685 & 0.0918 & 0.1 & 0.1842 \\
0.0534 & 0.0716 & 0.1053 & 0.0684 & 0.0359 & 0.0666 \\
0.0801 & 0.0677 & 0.1748 & 0.0684 & 0.0732 & 0.1464 \\
0.0545 & 0.0872 & 0.1463 & 0.0894 & 0.0487 & 0.0968
\end{array}\right) \\
D_{w}^{-} & =\left(\begin{array}{cccccc}
0.15 & 0.15 & 0.25 & 0.15 & 0.1 & 0.2 \\
0.0534 & 0.0677 & 0.1128 & 0.0684 & 0.0392 & 0.0666 \\
0.0936 & 0.0797 & 0.1293 & 0.0942 & 0.0359 & 0.0682 \\
0.15 & 0.1329 & 0.25 & 0.15 & 0.1 & 0.2 \\
0.0746 & 0.15 & 0.1258 & 0.15 & 0.0406 & 0.0744 \\
0.1409 & 0.0983 & 0.1463 & 0.0969 & 0.0554 & 0.0984
\end{array}\right)
\end{aligned}
$$

Step 6: calculating grey incidence distance degree according to Eq. $7 \sim 8$

$$
R_{1}=\frac{L_{1}^{+2}}{L_{1}^{+2}+L_{1}^{-2}}=0.0079, R_{2}=0.2855, R_{3}=0.9940, R_{4}=0.4059, R_{5}=0.5871
$$

step7: To sequence the course according to the figure of grey incidence distance degree, evaluation results vary from the optimal to the worst: $\mathrm{C}_{1}, \mathrm{C}_{2}, \mathrm{C}_{4}, \mathrm{C}_{5}, \mathrm{C}_{3}$. According to the evaluation type, course $C_{1}$ belongs to type $A$, course $C_{2}, C_{4}$ belong to type $B$, course $C_{5}$ belongs to type $C$, course $C_{3}$ belongs to type D.

\section{Conclusion}

Combining ideal solving method and Euclidean distance, the paper constructs a new course evaluation model based on grey correlation analysis method, and applies it to a course evaluation. The result of evaluation is in accord with the actual condition. The model increases the difference of course evaluation, and enhances the accuracy and practicability of course evaluation. The model constructed in the article doesn't analyze the quantified indicators and determination of indicators weight in detail. In this aspect, combination of fractional order and analytic hierarchy process to perfect course evaluation model is workable. Besides, data volume used in the evaluations is huge, the calculating process is rather complex which is hard for manual computation, so the next step is to design and fulfill a course evaluation system which is easily operated and better meets the actual reality, write algorithm to collect experts' evaluation data through computers and then take fuzzy processing. 


\section{References}

[1] Wang Tao, Fang Zhi-geng, Wu Hui and etc, Study on knowledge flows of disciplinary construction and innovative strategy based on the complex networks[C]//Proc of the IEEE conference on Grey Systems and Intelligent Services, (2007)1650-1654.

[2] Tao Wang, Linli Wu, Ji Zhang, The military academy teaching quality's grey correlation evaluation model and its application[C]/Proc of the IEEE conference on E-business and E-Government, (2012)2252-2255.

[3] Liu Si-feng, Dang Yao-guo, Fang Zhi-geng and etc. Grey System Theory and Its Application[M]. Beijing: Science Press, 2010.

[4] Wang, Tao, Ma, Guang-Bao, Wu Lin-Li, Identification of important sections for emergency rescue road network $[\mathrm{C}] / /$ Proc of the IEEE conference on Industrial and Information Systems, (2010)529-532. 